\title{
Primary school children's interaction with library media: information literacy in practice
}

\author{
PenNy MOORe \\ Ministry of Education, Private Bag 1666, Wellington New \\ Zealand, email: penny.moore@minedu.govt.nz
}

\begin{abstract}
In the context of a study of professional development in relation to information literacy, children at four primary schools were observed as they worked with a variety of media in various curriculum areas. The challenges they encountered are discussed against the background of the teachers' understanding of information skills and resource-based leaming.
\end{abstract}

Educators and librarians have acknowledged that the skills that constitute information literacy are becoming crucial to everyday life. However, it is suggested by some that students in general are not being equipped to meet those demands in the 1990s any better than they were in the 1980s. For example, since 1981, when Marland published Information skills in the secondary curriculum, there have been many initiatives to develop and promote the teaching of information skills in schools. Much of the widely disseminated research prompted by that report and reviewed by Rogers (1994), confirms that the original working party recommendations remain relevant today. Indeed, Rogers quotes extracts from British government reports which suggest the overall picture in schools has not changed significantly at all.

The fact is that library and study skills have been taught in schools for nearly a hundred years, but many students still cannot easily find and critically use information. In some schools, information literacy is enhancing teaching and learning, but the information age has yet to reach others. Information technology and pressures on library resources and services can, in this context, be seen as a catalyst for critically examining teaching techniques necessary for fostering information literacy.

Poor performance in finding and using information has in the past been attributed to a lack of explicit classroom attention to the cognitive aspects of the task (e.g. Irving, 1985; Kuhlthau, 1987). Yet the thinking underlying information literacy may be hidden from teachers and few studies illuminate process issues from the viewpoint of the students themselves. Further, whereas twenty years ago we focused on getting our most able students to think critically and do "research projects" at school, we now face the challenge of helping our least able students to solve information problems efficiently. Consequently

1 Funding received for this project from the Ministry of Education, Wellington, New Zealand is gratefully acknowledged.

Education for All: Culture, Reading and Information, IASL, 1998 
three factors are of central concern in developing information literacy. One is the nature of information literacy itself, the second is teachers' understanding of that concept and the third relates to the conceptions of inexperienced information users.

\section{The research context}

These three concerns and their interactions were the focus of the study reported here. New Zealand's National Curriculum gives information skills a high profile by listing them as "essential skills," to be taught at all levels in all subjects. However, a survey by Chalmers and Slyfield (1993) found that more than two thirds of the teacher participants recognized that they personally required training in information skills. Thus the current study began with an assessment of school-wide support for information literacy development and a survey of all teaching staff in four suburban primary schools to investigate their interpretation of "information skills," "resource-based learning" and the role of the library in teaching and learning. The schools were spread across socio-economic sectors, but none had qualified full-time staff in their libraries.

Following "information climate" assessment, a group of three or four teachers at each school participated in a series of workshops on teaching information problem solving to children aged between 7 and 11. Workshops followed a general pattern, but were tailored to actual curriculum delivery in each school. Typically, they began with a focus on teachers' information literacy and then explored implications of the challenges experienced in terms of teaching children the same skills. A fortnight later, children were observed as they engaged in information handling across a range of curriculum areas. The researchers' observational data were discussed with participants to provide further insights into the experiences of children.

Some 260 children were observed in the course of the year, sometimes singly, sometimes in groups. The children themselves responded to questioning about task procedures and expectations, together with information handling and conceptual knowledge.

\section{Teachers' understanding of information skills}

The majority of teachers surveyed agreed that ability to apply information skills is essential to life-long independent learning. However, definitions of the skill set varied. More than two thirds of staff in three schools agreed that information skills are the same as research skills. In one of those schools, $64 \%$ teachers also responded that they were the same as library skills, but staff in other schools disagreed. In the fourth school, stafi did not strongly identify information skills with either library or research skills.

The implications are that in some schools, teaching library skills may be seen as sufficient for promotion of information literacy, whereas in others, a combination of library and research skills might be taught to reach the same goal. Either way, the requirement to teach "information skills" could be interpreted as simply repackaging the curriculum content of earlier times. While this may not be seen as adequate by information literacy experts, one wonders what information skills, if any, are being taught in the school where neither library nor research skills gained clear support as components of information skills. 
The same issues arise in relation to information technology. This was not seen as the over-riding concern of information skills in any school, but just over half the teachers in two schools thought information skills were mostly about using information technology. Thus one might expect those teachers to emphasize information technology at the expense of other aspects of information skills. However, asked whether children's information skills would arise naturally, just over half the teachers in all schools agreed. This would suggest that many teachers saw little need to explicitly teach information skills of any kind.

Despite the above, most teachers believed they had a "practical understanding" of information skills, but again around half of them then responded that they were unfamiliar with ways in which the process of finding and using information could be broken into steps for teaching. In one school $78 \%$ of teachers responded in this way. Where teachers did give an indication of information problem solving steps, they often focused on defining needs and locating information, without giving attention to what is done with it. (Thus emphasizing the library skills end of the continuum.)

It is thus not surprising that no more than $27 \%$ of responses in any school indicated that information problem solving models were always or often used in planning learning activities.

\section{Teachers' understanding of resource-based learning}

In the course of resource-based learning activities, children's attempts at information problem solving can be made clearly evident and component skills can be addressed. Teachers surveyed were generally agreed that resource-based learning promoted children's abilities to work co-operatively. A very high percentage of teachers expected resource-based learning at least sometimes to promote independent learning, foster particular information skills, critical thinking and working at one's own level. The percentage in each school claiming this was always the case varied considerably, with one school trailing the others significantly (e.g. $55 \%$ lower than the highest rating for each factor).

That cognitive benefits were not expected to be consistently high might result from the fact that at most only $57 \%$ of the teachers always had clear objectives or outcome measures for resource-based learning. The percentage having explicit objectives for teaching information skills was even lower - just 46\%. Not surprisingly, children's grip on the purpose underlying such activities was not expected to be particularly sound. If the children do not understand the purpose, development and application of strategic knowledge is likely to suffer.

In addition, there were some inconsistencies in teachers' thinking about conceptual support for resource-based activities. For example, staff agreed that they personally find it easier to unearth relevant information when they already know something about a topic. They also agreed that without guidance children can miss basic concepts. However, these perceptions did not always lead teachers in the lower socio-economic schools to introduce topic fundamentals or provide a context for information seeking. Children could be sent to search for information independently with very little conceptual support. Despite this, children were generally expected to have a clear idea of the information they were seeking. 
Teachers across all schools seemed to waiver in their expectations concerning children's ability to find information. Independent selection of sources was not expected to occur frequently in any school, yet children were sometimes expected to complete resource-based learning activities at home where consistency of support and access to resources is highly variable. In two schools the majority of staff agreed that good information skills were essential for resource-based learning success. In the other schools opinion was almost evenly divided between agreement and disagreement. This appears to be a chicken and egg situation, children need the skills to do the task which will develop the skills. Assumptions about natural skill development are likely to determine the level and kind of teaching support provided.

The four schools participating in the study also varied in their attitudes to the role of the library in supporting information problem solving. Indeed, although nearly all teachers expected children to use the library to find information, only in one school was absence of a library unanimously expected to impact equally on teaching and learning. In the other schools, children's learning was expected to suffer more than teaching. Teachers in all four schools were uncertain whether the library was central to learning.

This then is the backdrop against which we must view the children's experience of information problem solving. It is one in which the teachers demonstrate little coherence of thought or action in support of information literacy and little explicit teaching of information skills.

\section{The model of information problem solving applied in workshops}

The task of finding and using information has been characterized in many models, most of which list a series of steps or phases and the skills essential to each (e.g. Irving, 1985; Eisenberg \& Berkowitz, 1990, Kuhlthau, 1987). In contrast, Moore (1996) developed a dynamic model, based on empirical research, which incorporates recognition of the thinking process that coordinates the entire information problem solving routine. Figure 1 below illustrates that the process is not only continuous, but that the outcome of each phase influences which one will follow.

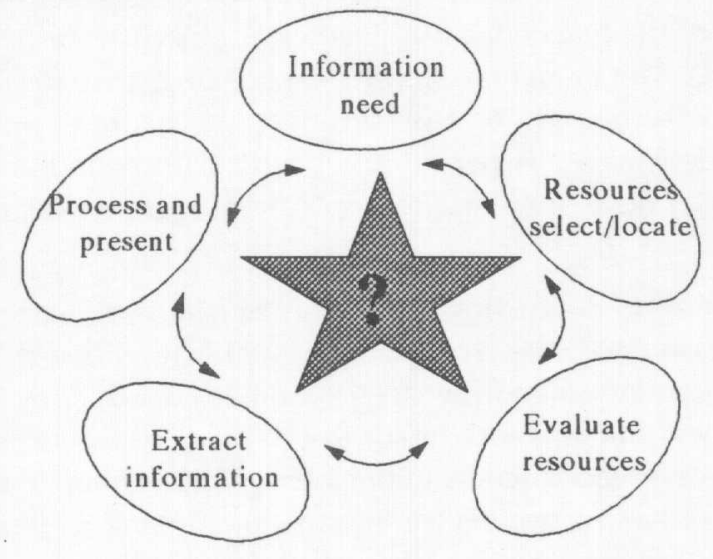

Figure 1: Dynamics of information problem solving (Moore, 1996) 
The central task is that of questioning as this, be it automatic and covert or slower and guided by a teacher, is essential during all phases of the process. Self-questions focus on information needed, monitoring and directing progress through the complex problem, current understanding of information found and its relation to the original information problem. Thus events in each phase influence those that follow as well as the nature of the overall information problem solution.

This model provicled the structure for workshops with teachers and the focus of attention for classroom observations. Although each phase was addressed separately, the continuity of the process was also kept in view. Thus brainstorms used for defining an information need were followed through to selection of resources and exercises in note taking were followed through to final presentation. In the section that follows, children's experiences with library media are described and contrasted with teachers' expectations.

\section{Students' experiences}

Much of the information handling seen at all levels in each school involved talk rather than text, although the emphasis on text and graphic information sources increased as children progressed through the grades. Teachers recognised that every aspect of resource-based learning presents difficulties for some children. The examples discussed should be treated as case study material to sharpen personal observation and prompt questioning. Broad generalisation cannot be justified.

\section{Searching for information}

Teachers in all schools expected children to have a clear idea about the information they sought, and to seek assistance in finding it. However, instructions and materials were not always helpful.

For example, two 8 year olds were sent to the library "to find all the books" they could on bones. As they examined two books about the human body, they were asked how they could find out about bones. They agreed that they would look at pictures and read the book, but added that they read "only the important bits." However, they had no way of identifying these. Asked how they could find other books in the library, the boy looked totally blank, but the girl, new to the school, looked around while describing a card catalogue. A computer was in evidence, but it was switched off and the children could not access it.

The observer spotted a row of encyclopedia. She was informed that these could not be used "because they were all dusty." Despite this, the girl started searching them with enthusiasm and a small prompt drew in the boy. While examining the books he suddenly realized that animals have bones, so they could look for animal books too! However, he said he did not know where to look. A prompt sent both children back to the non-fiction section where with considerably more enthusiasm he began looking at contents pages and reading out chapter headings while giving a running commentary on the probable content (just as modeled by his teacher). In this case, the randomness of the search contrasted sharply with the practiced process of determining which chapter would be valuable. 
These children did not have much idea of what would be done with the information once found, but during an expository writing exercise a pair of nine year olds were observed seeking information about telephones. They began searching non-fiction shelves at 300 "because this is where you find them." Once they had been prompted to identify a more appropriate Dewey number using the catalogue, they based their shelf search on the assumption that shelving was continuous around the whole room, when in fact shelving bays had been used.

The first index examined made no mention of telephones. With a little assistance they next tried an encyclopedia, one girl opting for the $T$ volume and the other selecting the index volume. The $T$ volume did mention telephones and enabled the girl to complete all sections of her worksheet, although the text was difficult. In contrast, the index volume provided the other searcher with five different entries. Surprisingly, the girl looked up each in turn, locating only single word references, none of which met her information need. Independently she identified and located an alternative source using a keyword (communication) recognized incidentally in searching the other sources. In this instance, the more sophisticated strategy demanded greater tenacity. It did achieve the location of more easily understood information, but that is not necessarily rewarding.

In terms of classroom strategies for improving information skills support, it seemed essential that the children had a clear idea of the purpose for which they were seeking information. One teacher created an activity linking purpose and appropriate resource selection. Children examined magazines, the class collection of CD-ROMs, dictionaries, encyclopedia and school journals for information on aspects of space with the secondary task of reporting on which sources proved to be useful. They told the researchers that it was easy to find information in dictionaries and on CD-ROM, but it was difficult to understand, whereas the encyclopedia met their needs perfectly. Normally these children would give up after the first source that failed to meet their needs. In the context of "seeing which resources help" they were prepared to search much further and to begin building a concept of appropriate information resources.

\section{Conflicting information}

Between half and 90\% of teachers surveyed in all schools expected children to look at more than one relevant information source. In workshop discussion it was evident however, that they had not thought about supporting children in resolving information conflicts. In contrast, a brainstorm with 8 to 10 year olds on the nature of information, showed that they were well aware of the problem, but did not have strategies to apply.

Two levels of information conflict were apparent during this study. In the first, actual presentation of information caused difficulties, whilst in the second confusion arose when prior knowledge led children to challenge text.

A mixed age class was observed near the end of a unit about planets. The teachers had prepared an exercise in matching planet names to cards labeled by color and diameter. Instructions were very clear and the children were reminded to apply what they already knew, but to use the classroom resources when they got stuck.

Different resources illustrated planets using different colors. The answer for children in one group was simple, take all answers from one book and ignore the rest. Asked what else 
they could do in this situation, they suggested guessing. It was not so simple for three 10 year old boys. There was no difficulty locating relevant information within a book (albeit searching randomly), but while it illustrated the size of the sun and presented the planets in color, size and sequence across the bottom of the double page spread, it also showed a diagram of planet orbits. In this, all planets were the same size and a key was used to show which colour dot represented which planet. Earth in the schematic was red and at the bottom of the page was blue-green!

One boy claimed the book was wrong. When questioned, he modified this saying that only parts of the book were wrong, just those bits that were not the same as his memory. One of the others was convinced he had the right answer. Asked to explain, he pointed out that in his book the schematics used colored lines for the orbits, but on closer inspection it was found that they did not match the color used for the actual planets.

The problems continued when it came to determining the diameter of the planets. The children now had two books, together with the cards the teacher had prepared. One book quoted sizes to the nearest kilometer, the other rounded them to the nearest 100 kilometers except for Earth which was exact. One of the books differed by 1000 kilometers from the figures the teacher had used in constructing cards. A novel solution was to examine the cards themselves and match them to the chart by fragments of lines used in their construction. The boys finally selected a book on the basis that it had some numbers the same as those provided by the teacher, but they experienced some difficulty comparing these large numbers and ordering them appropriately.

The teacher concerned had planned carefully and gone to some trouble to prepare materials. She did not expect such conflicts to emerge, but the result was that the entire class learned something about the ways information is packaged for publication.

The other example of conflicting information led to cuncept building. Nine and ten year olds were asked to examine books about energy and to apply their knowledge to identify appropriate definitions. The secondary task was to report on how they had searched the resources and what made them think a book was "good." They ran into some problems which were a function of conventions used in publishing (e.g. an index used bold font for some pages numbers, but the explanation was hard to find) and made strategic use of other knowledge (the introduction often contains definitions of the topic covered). The challenge level rose when they began to look at additional books. A girl looked particularly puzzled and explained that while one book said that the total amount of energy remains the same, it just transforms from one type to another, a second book announced that energy was becoming scarce.

This provoked a deep discussion between two children. It grew when two others struck the identical issue using different books and resulted in an exchange where the four of them argued for a position by referring to the exact text. One of the four finally came to the conclusion that both perspectives could be correct. She demonstrated understanding that as energy sources changed, they could become less easily accessible. However, the social pressures of arguing the point caused her to back down, although her non-verbal language indicated the others had not convinced her they were right.

In the first example, conflicting information inhibited completion of the task, but was used to promote understanding of information packaging and publishing. In the second case, it 
led to deep processing of knowledge and an adjustment of understanding. Both experiences were unexpected outcomes of the lesson which may have been ignored had they occurred outside the context of research. We know very little about ways children usually cope with this sort of situation, yet it is at the heart of learning.

The exercise described allowed the teacher concerned to see how much children knew about evaluating and searching texts. This was more than he expected, but after discussing how they had looked for information and the challenges found in the books, he observed that the children became more selective and systematic when working independently. In addition, both the teacher and the children left the exercise spontaneously expressing pleasure in the interactions and the learning.

\section{Reading and evaluating information}

Although teachers surveyed recognized that evaluating information is difficult for children, half to three quarters of them expected children to read, interpret and evaluate information found. The example involves 8 and 9 year olds using question frameworks constructed by the teacher (What is your invention, what parts does it have, how does it work...) as an introduction to expository writing. The boys observed were very clear about the purpose and first step in the task.

One used a table of contents including icons with chapter headings to select a chapter on clocks. The other boy said he would choose a topic using the contents table and index, but actually did so by flicking through the pages looking at pictures.

Answering the questions and reading the books were both seen as the next tasks, but neither boy seemed to know how to proceed, rather they engaged in a range of avoidance activities. Mild frustration seemed to arise and one boy sought assistance in changing topic. The book he had did not have a contents table and the index was found to be totally inadequate as it did not even contain references to the major subjects in the book. This book was designed for a browser rather than a purposeful information seeker.

The boys did very little reading and indeed, it would not have helped much as neither book contained the technical information the boys required. The information could be inferred from the pictures if one had background knowledge, but there was a major conceptual problem for one of the boys. He could not imagine things working without electricity! It was impossible to see where one might insert batteries into a sundial or a water clock, and clockwork mechanisms were not shown in detail.

Meanwhile his friend had found a clear diagram of a clock and as he wrote down the main components, he read them out. However, he was evidently dissatisfied and disappeared only to return with a book brought from home, already open at a page on clocks. This provided an even better diagram, but both boys had great difficulty shaping their ideas into something they could write down. Pendulums, cogs and springs were quite novel. One boy demonstrated verbal understanding of some central concepts, but this did not appear in his writing. The second boy wrote more extensively, but did not seem to have as high a level of understanding. The final product was an inaccurate reflection of their achievement and tenacity. 
In a workshop activity teachers were asked to specify learning objectives for a hypothetical learning activity, to list some questions children were likely to ask and to evaluate a set of non-fiction resources on the subject. Their criteria for evaluation centered on children's reading ability, resource attractiveness and pictorial content, with a few references to the presence of search aids such as indexes, contents tables and headings. When asked to answer the hypothetical children's questions using the books they rated as "good," teachers were often surprised by the difficulty of the task and the degree of prior knowledge involved.

Discussing how information is packaged and making public one's own thinking in searching seems to support development of a flexible range of approaches to information seeking. Several participating teachers commented that where children would once say a book had none of the required information, they had begun spontaneously explaining what they were seeking and asking how they could search a particular resource differently.

\section{Extracting information and taking notes}

The task of note taking was given a low priority at primary school level although teachers were keen to develop the skills with their classes. The examples discussed involve older children working without teacher assistance and young ones being led through the task.

During a school building program, two classes had been relocated and to compensate for the temporary reduction in information sources, teachers had unearthed a film strip projector and several rolls of film. As part of a study of forest life, 10 to 11 year old girls were viewing the strips, taking notes and producing summaries. They found use of the old technology highly motivating because it was new to them.

The first strip consisted of photographs focusing on feeding habits of birds. Each had a sub-title and no further text information. The girls carefully wrote down the sub-titles, but did not examine the pictures closely. They did not seem to be processing the pictorial information or relating it to their recent forest trip and there was very little discussion. When one film strip had been viewed, the girls decided they should get more information, but one held up another strip saying, "We can't do this one, it's all pictures!" while a second found a strip in which pictures were interspersed with text frames. "Hey, this one has got some info!!" They were asked whether they got more information from pictures or text and two agreed that text is more important, but the third said information came from both. She added that the text is needed to sort out confusion when pictures and text do not match. In the context of their understanding of this exercise, pictures were not important.

Comparison of the film strips, the children's notes and the summaries written, showed that notes on the first strip were a direct copy, while those on the second showed only minor changes. The summaries themselves provided little evidence of re-organizing or re-wording the information, although one girl had combined two statements from different parts of her notes. Another girl added a critical comment about a gap in the information. Looking at these three elements provided considerable insight concerning their information skills. Integration of information across the range of activities presented was not evident but then the relationship was not made explicit to the children.. 
Children are sometimes expected to extract relevant information from videos and on one occasion one of the teachers took notes on the content of a video on growing plants. She commented on awareness that she was using prior knowledge that was not likely to be available to 8 and 9 year olds. The video began by showing how a lima bean can be placed in a glass container with paper and will grow with the addition of water. Some children believed the evidence of their eyes and noted that the seed was put in or needed water. One supposedly less able girl's notes for the entire video said that the bean would take two or three weeks to grow and would need love and sunshine. This was accurate to the video content, but her published work stated that,

"you don't need to give it soil to grow some of the time it takes about three or four weeks to grow. Always got to water it it needs a lot of love and sunshine." (sic)

She was the only one to recognize the implication of what was seen - soil is not always needed for growth. In contrast, taking an accurate note does not imply its use in later work either. Another girl recorded the fact that beans can grow in water, but this apparently conflicted with her experience and her published work said,

"Plant's start their life by being a seed in a pot of soil of course." (sic)

Despite the accuracy of her notes on the entire video, she went on to add information about blood and bone, fertilizer and zoo compost, none of which were mentioned in the video. Thus in this case, information from a variety of classroom exercises was integrated.

None of the children observed recorded irrelevant material and none gave in-correct information in their written work. This was remarkable since the video wrapped the target information in a wealth of extraneous data. Several children added accurate recollections from previous activities.

Children commented that note-taking was difficult, some blaming the speed of speech and the accents of speakers and others thought it did not have as many facts as a previous video. Despite the difficulties, a few children were seen to write summaries that gave sound overviews without getting bogged down in detail.

"There are lots of ditferent ways that plants can grown from. They can grow from potatoes and also by cutting a leaf from a particular type of plant and planting it in a pot and then within 2-3 weeks roots will start to grow and within 3-4 weeks the plant will probably start to grow leaves and a stem." ( 9 year old boy.)

A key element in the success of this exercise was that the teacher taking notes herself was aware when the tape should be stopped to allow concentrated writing. She and her colleague had prepared the children for note taking with discussion of keywords from a shared reading on plants and made links between activities very clear. At the conclusion of the video, children were asked to share their notes with a partner and to discuss whether they could make a summary from each others notes, what was missing, what needed checking and how they had approached the task. This reflection on process let children see the range of strategies used (some quite complex) and helped them focus on the purpose of note taking. Again, the teachers were pleased with the level of achievement demonstrated. 


\section{Conclusion}

This report does not do justice to the richness of the data collected, but does indicate some of the challenges that children face in handling a variety of information sources and ways teachers can support them. A theme that emerged time and again was that information is gathered for a purpose, to solve some sort of information problem. Children's understanding of that purpose is often a function of teacher instruction and this influences their interpretation of the task and all facets of their information problem solving attitudes and actions.

Teachers were surprised by the sophistication of children's thinking in some cases and dismayed by lack of skills in others, but all emerged with a clear understanding of the need to address information problem solving skills explicitly in the classroom. Since the demands of the materials vary, it was also clear that simple rule transmission is inadequate. Instead children need to develop an understanding of the information world that promotes choice among resources, builds flexibility in searching and encourages critical thinking about information and the overall information problem solving process. The most compelling aspect of the study for some of the teachers was the change they observed in children's learning outcomes.

\section{References}

Chalmers, A. \& Slyfield, H. (1993). Contributions to learning: libraries and New Zealand schools. Wellington: Research Unit, National Library of New Zealand.

Eisenberg, M. \& Berkowitz. (1990). Information problem solving: The big six skills approach to library and intormation skill instruction. N.J.: Ablex.

Irving, A. (1985). Study and information skills across the curriculum. London: Heinemann Educational.

Kuhlthau, C. C. (1987). Information skills: Tools for learning. School Library Media Quarterly, Fall, 22-28.

Marland, M. (1981). Information skills in the secondary curriculum. London: Methuen.

Moore, P. A. (1995). The dynamics of information problem solving. Set, 2 item 3, 1-4.

Moore, P. A. (1996). Information literacy: the importance of questions. SCAN 15 (1) 43-46.

Rogers, R. (1994). Teaching information skills: A review of the research and its impact on education. London: British Library Research. 